\title{
Knowledge of antibiotic use and resistance among students of a medical school in Nigeria
}

\author{
Ijeoma Okedo-Alex ${ }^{1 *}$, Ugochukwu C. Madubueze ${ }^{1}$, \\ Chukwuma D Umeokonkwo ${ }^{1,2}$, Onyinyechukwu U Oka, \\ Azuka S Adeke ${ }^{1,2}$, Kingsley C Okeke ${ }^{1}$
}

1. Department of Community Medicine, Federal Teaching Hospital Abakaliki Ebonyi State Nigeria

2. Nigeria Field Epidemiology and Laboratory Training Programme Asokoro Abuja Nigeria

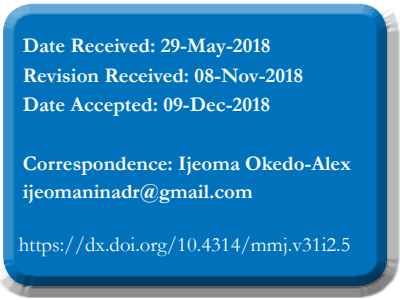

\section{Background}

\section{Abstract}

Antimicrobial resistance presents a growing concern worldwide. Medical students are potential antimicrobial prescribers and stewards following graduation as doctors. The aim of this study was to assess the knowledge regarding antibiotic use and resistance among prefinal year and final year medical school students of Ebonyi State University, Nigeria.

Methods

A cross-sectional study was conducted among all the 184 pre-final and final year medical students of the College of Medicine at Ebonyi State University, Nigeria. Information was collected in April 2018 using a semi-structured, self-administered questionnaire and data were analysed with Epi-Info Version 7.2. Analytical decisions were considered significant at $\mathrm{P}<0.05$.

\section{Results}

Respondents were mostly males (62.5\%), aged 20-29 years (68.9\%) with $60.9 \%$ of them in the final year class. Eighty-seven percent of them desired more education on antibiotic use and resistance. Majority 119 (64.7\%) respondents had good knowledge of antibiotic use and resistance, however, 39\% incorrectly answered that bacteria cause common cold. Only $103(56.0 \%)$ of them had positive practice of antibiotic use. While $8.2 \%$ of respondents always consulted a doctor before starting an antibiotic. $37.2 \%$ of them never discarded their remaining leftover medications. Knowledge was associated with respondent's gender $(\mathrm{P}=0.035)$ while practice was associated with the class of study $(\mathrm{P}<0.001)$.

\section{Conclusion}

There was good knowledge of antibiotic use and resistance, however, practice levels were poor. There is need to enrich existing courses and training about antibiotic use in the curriculum of the medical schools with more emphasis on antimicrobial stewardship.

Key Words: antibiotic use and resistance, medical students, knowledge, practice, Nigeria

\section{Introduction}

Antimicrobial discovery has been posited to be the single greatest historical advancement in health care. Following the antimicrobial innovation and their widespread use, there has been a conspicuous reduction in the morbidity and mortality associated with a host of formerly fatal diseases. However, the widespread use of antimicrobials has been associated with the emergence of resistance to these agents ${ }^{1}$. Antimicrobial resistance (AMR) makes previously effective treatments to become ineffective and leads to persistent infections and increased risk of spread to others ${ }^{2}$. AMR has continued to threaten the effective prevention and treatment of a wide range of infections as it increases the cost of healthcare (due to lengthier stay in hospital, additional investigations and use of more expensive medications) and prolongs disability ${ }^{2}$. Although AMR could occur naturally over time usually through genetic changes, the misuse and overuse of antimicrobials are accelerating this process. Some factors that influence the occurrence of AMR problems include the availability of antimicrobial drugs without prescription, inappropriate physician prescription, and inappropriate practice of AMR prevention and control among health care workers ${ }^{3}$. Therefore the role of doctors and other healthcare workers in reversing the scourge of AMR cannot be overemphasized. Studies have shown that both doctors and medical students agree that AMR is a global public health problem closely linked to inappropriate antimicrobial use. Adequate knowledge of AMR and AMR prevention were also deemed important ${ }^{4,5}$. In spite of this, low confidence in the choice of correct antibiotics and self-medication practices have been reported among medical students ${ }^{5-9}$. Medical students being potential doctors who will have to act as patient educators, prescribers and role models of correct antimicrobial use need to be armed with adequate knowledge of AMR and antimicrobial stewardship. Their sound knowledge on AMR should be in addition to their correct personal use of antibiotics. The findings of this study will be useful in the design, inclusion, and implementation of effective antimicrobial stewardship training for medical students. The objective of this study was to assess the knowledge regarding antibiotic use and resistance among pre-final and final year medical school students of Ebonyi State University, Nigeria.

\section{Methods}

\section{Survey setting and design}

This was a descriptive cross-sectional study of all pre-final (penultimate) and final year medical students at the medical school, Ebonyi State University Nigeria. These students 
have completed their basic training in pathology (medical microbiology inclusive) and pharmacology at the 4th year level. Ebonyi State University is the foremost university in Ebonyi State, Nigeria. It is the only university currently training student doctors in the state and has produced several sets of doctors since its inception in 1999. As part of the training of medical students, they are exposed to teachings on disease conditions (pathology) and mechanisms of drug action and use (pharmacology) in the $4^{\text {th }}$ year of medical school as this knowledge will serve as the basis for their training in clinical medicine in the $5^{\text {th }}$ and final year. Following this, they will become doctors and prescribe drugs including anti-microbial medications in addition to performing other clinical duties to patients. This study was conducted in April 2018 and as of that time, there were 112 and 72 medical students in the final and pre-final classes.

\section{Study population and data collection}

Data were collected from 112 final and 72 pre-final year medical students $(100 \%$ response rate respectively). Information was collected using a semi-structured, self-administered questionnaire adapted from previous studies10-12. The first section of the questionnaire collected information on the socio-demographic characteristics of the students while the second section was on knowledge of AMR (Yes/No and True/False) answers. In the third section, Antimicrobial usage/practice was assessed using 4-point Likert scale questions with responses ranged from "Never" to "Always. Data were collected by the research team on a scheduled week-day just before the first lecture of the day. The research team was made up of senior resident doctors in the Department of Community Medicine, Federal Teaching Hospital Abakaliki (FETHA)

\section{Data management/analysis}

The independent variables were socio-demographics (age, sex, class, ever been taught on AMR), perceived adequacy of AMR knowledge and desire for more AMR education. Dependent variables were knowledge towards AMR and antibiotic usage practices.

A total of 5 questions (True/False) were used to assess knowledge of AMR and was scored 2 points per correct answer. Based on this, knowledge was categorised into poor knowledge ( $<7.5$ points) and good knowledge ( 7.5 points and above). Nine questions on a four-point Likert scale assessed antibiotic usage practices. A score of $75 \%$ and above was taken as good practice while less than $75 \%$ constituted bad usage practice.

Epi-Info Version 7.2 was used for the data entry and analysis. Frequencies and proportions were calculated for categorical variables while means and standard deviations were calculated for numeric/quantitative variables. Frequency tables were used to present the descriptive statistics of the variables. Chisquare statistics was used for bivariate analysis.

\section{Ethical considerations}

Ethical clearance for this study was obtained from the Research and Ethics Committee of Federal Teaching Hospital Abakaliki, Ebonyi State, Nigeria. Written informed consent was obtained and confidentiality ensured.

\section{Results}

One hundred and fifteen $(62.5 \%)$ of the respondents were males, $126(68.5 \%)$ were aged $25-29$ years and $112(60.9 \%)$ were in the final year class [Table 1].
Table 1: Socio-demographic characteristic of respondents

\begin{tabular}{lcc}
\hline Variable & Frequency $(\mathrm{n}=184)$ & Percentage $(\%)$ \\
\hline Gender & & \\
$\quad$ Male & 115 & 62.5 \\
Female & 69 & 37.5 \\
Age group (years) & & \\
$20-24$ & 38 & 20.7 \\
$25-29$ & 126 & 68.5 \\
$30-34$ & 16 & 8.7 \\
$35-39$ & 4 & 2.1 \\
Mean age 26.5 2.76 & & \\
Class of study & & \\
$5^{\text {th }}$ year & 72 & 39.1 \\
$6^{\text {th }}$ year & 112 & 60.9 \\
\hline
\end{tabular}

One hundred and seventy-seven $(96.2 \%)$ respondents correctly linked indiscriminate use of antimicrobial drugs to the development of antimicrobial resistance. Seventy-two (39.1\%) of the students did not know that common cold and influenza were not due to bacterial causes. Most (98.4\%) of the respondents knew that antimicrobial resistance was an important global public health issue and $87.0 \%$ of them wanted more education on antimicrobial use and resistance [Table 2].

Table 2. Knowledge of antimicrobial resistance among the respondents

\begin{tabular}{|c|c|c|}
\hline Variable & Frequency $(n=184)$ & $\begin{array}{c}\text { Percentage } \\
(\%)\end{array}$ \\
\hline \multicolumn{3}{|c|}{$\begin{array}{l}\text { Indiscriminate use of } \\
\text { antibiotics leads to } \\
\text { emergence of resistance }\end{array}$} \\
\hline True & 177 & 96.2 \\
\hline False & 7 & 3.8 \\
\hline \multicolumn{3}{|c|}{$\begin{array}{l}\text { If antimicrobials are taken } \\
\text { too often, they are less } \\
\text { likely to work in the future }\end{array}$} \\
\hline True & 141 & 76.6 \\
\hline False & 43 & 23.4 \\
\hline \multicolumn{3}{|c|}{$\begin{array}{l}\text { Bacteria cause common } \\
\text { cold and influenza }\end{array}$} \\
\hline True & 72 & 39.1 \\
\hline False & 112 & 60.9 \\
\hline \multicolumn{3}{|c|}{$\begin{array}{l}\text { Antimicrobial resistance is } \\
\text { an important/serious global } \\
\text { public health issue }\end{array}$} \\
\hline True & 181 & 98.4 \\
\hline False & 3 & 1.6 \\
\hline \multicolumn{3}{|c|}{$\begin{array}{l}\text { Ineffective treatment can } \\
\text { occur due to indiscriminate } \\
\text { and injudicious antimicrobial } \\
\text { use }\end{array}$} \\
\hline True & 178 & 96.7 \\
\hline False & 6 & 3.3 \\
\hline \multicolumn{3}{|c|}{$\begin{array}{l}\text { Would like more education } \\
\text { on antimicrobial use and } \\
\text { resistance }\end{array}$} \\
\hline Yes & 160 & 87.0 \\
\hline No & 24 & 13.0 \\
\hline
\end{tabular}


A high proportion of the students $(69.6 \%)$ sometimes consulted a doctor before using antibiotics, $11.9 \%$ usually did so but only $8.2 \%$ of them always consulted a doctor before using antibiotics. About $41 \%$ of our respondents never stopped taking their antibiotics when they felt better, $36.6 \%$ sometimes and $13.1 \%$ usually stopped taking their antibiotics when they felt better. Additionally, $37.2 \%$ of our respondents never discarded their leftover antibiotic medications, $35.5 \%$ sometimes did and $16.4 \%$ always discarded their leftover medication. Overall knowledge rating of knowledge of antimicrobial resistance revealed that 119 $(64.7 \%)$ respondents had good knowledge whereas only 103 $(56.0 \%)$ respondents had good practice toward antimicrobial use [Table 3].

Table 3. Proportion of respondent with good knowledge of AMR and antibiotic usage

\begin{tabular}{lcc}
\hline Variable & Frequency $(\mathrm{n}=184)$ & Percentage \\
\hline Knowledge status & & \\
Good knowledge & 119 & 64.7 \\
Poor knowledge & 65 & 35.3 \\
Practice status & & \\
Good practice & 103 & 56.0 \\
Bad practice & 81 & 44.0 \\
\hline
\end{tabular}

More male respondents had a better knowledge of antimicrobial use and resistance than their female counterparts ( $70.4 \%$ vs $55.1 \%$; $\mathrm{P}=0.035)$. The proportion of respondents with good knowledge of AMR and antimicrobial use were more in the 30-34 age group compared to other age categories; however, this difference was not statistically significant $(\mathrm{P}=0.579)$. Eighty- three $(65.9 \%)$ had good knowledge of antimicrobial use. More respondents in the sixth year class had a better knowledge on AMR and antimicrobial use compared to those in the fifth year but this difference was not statistically significant $(69.6 \%$ vs $56.9 \%$, $\mathrm{P}=0.079)$ [Table 4].

Table 4. Factors associated with knowledge of antimicrobial resistance

\begin{tabular}{|c|c|c|c|c|}
\hline \multirow[t]{2}{*}{ Variable } & \multicolumn{2}{|c|}{ Knowledge Status $(n=184)$} & \multirow{2}{*}{$\begin{array}{l}\text { Chi } \\
\text { square } \\
\left(x^{2}\right)\end{array}$} & \multirow[t]{2}{*}{ P-value } \\
\hline & $\begin{array}{c}\text { Good } \\
\text { knowledge }\end{array}$ & $\begin{array}{c}\text { Poor } \\
\text { knowledge }\end{array}$ & & \\
\hline \multicolumn{5}{|l|}{ Sex } \\
\hline Male & $81(70.4)$ & $34(29.6)$ & 4.455 & $0.035^{*}$ \\
\hline Female & 38 (55.1) & $31(44.9)$ & & \\
\hline \multicolumn{5}{|c|}{ Age group (years) } \\
\hline $20-24$ & $22(57.9)$ & $16(42.1)$ & 1.967 & 0.579 \\
\hline $25-29$ & 83 (65.9) & $43(34.1)$ & & \\
\hline $30-34$ & $12(75.0)$ & $4(25.0)$ & & \\
\hline$=>35$ & $2(50.0)$ & $2(50.0)$ & & \\
\hline \multicolumn{5}{|c|}{ Class of Study } \\
\hline $5^{\text {th }}$ year & $41(56.9)$ & $31(43.1)$ & 3.093 & 0.079 \\
\hline $6^{\text {th }}$ year & $78(69.6)$ & $34(30.4)$ & & \\
\hline
\end{tabular}

*Statistically significant

More females had better use of antibiotics than their male counterparts but the difference was not statistically significant $(56.5 \%$ vs $55.7 \%$; $\mathrm{P}=0.908)$. The proportion of respondents with good use of antibiotic medications were more in the 25-29 age group compared to other age categories but the difference was not statistically significant $(\mathrm{P}=0.503)$. More respondents in the fifth year class exhibited good use of antibiotics compared to those in sixth year and this difference was statistically significant $(72.2 \%$ vs $45.5 \%$, $\mathrm{P}=<0.001)$ While more respondents with good knowledge also practised good antimicrobial use, the difference was, however, not statistically, significant $(59.7 \%$ vs $49.2 \%$; $\mathrm{P}=0.173$ ) [Table 5].

Table 5. Factors associated with antibiotic usage practices

\begin{tabular}{lllll}
\hline Variable & \multicolumn{2}{l}{$\begin{array}{l}\text { Practice } \\
\text { Status(n=184) }\end{array}$} & $\begin{array}{l}\text { Chi } \\
\text { square } \\
\left(x^{2}\right)\end{array}$ & p-value \\
& $\begin{array}{l}\text { Good } \\
\text { practice }\end{array}$ & $\begin{array}{l}\text { Bad } \\
\text { practice }\end{array}$ & & \\
& & & & \\
\hline Sex & $64(55.7)$ & $51(44.3)$ & 0.013 & 0.908 \\
$\quad$ Male & $39(56.5)$ & $30(43.5)$ & & \\
Female & & & & \\
Age group (years) & $20(52.6)$ & $18(47.4)$ & 2.350 & 0.503 \\
$20-24$ & $74(58.7)$ & $52(41.3)$ & & \\
$25-29$ & $8(50.0)$ & $8(50.0)$ & & \\
$30-34$ & $1(25.0)$ & $3(75.0)$ & & \\
$=>35$ & & & & \\
Class of Study & $52(72.2)$ & $20(27.8)$ & 12.666 & $<0.001^{*}$ \\
$5^{\text {th }}$ year & $51(45.5)$ & $61(54.5)$ & & \\
$6^{\text {th }}$ year & & & & \\
Knowledge status & & & \\
$\quad$ Good knowledge & $71(59.7)$ & $48(40.3)$ & 1.857 & 0.173 \\
Poor knowlegde & $32(49.2)$ & $33(50.8)$ & & \\
\hline
\end{tabular}

*Statistically significant

\section{Discussion}

Antimicrobial resistance presents a growing concern worldwide $^{13}$. Amongst other things, the irrational use of antibiotics has contributed to the progressive loss of bacterial sensitivity to antibiotics and spreading of resistant strains of bacteria, with substantial clinical and economic impact ${ }^{14}$. In this study, we assessed the knowledge regarding antibiotic use and resistance among pre-final and final year medical school students of Ebonyi State University, Nigeria.

Majority of our respondents (98.4\%) knew that antimicrobial resistance was a global problem and indiscriminate use of antimicrobials could cause resistance. This is in keeping with similar studies done among medical doctors and students where $98 \%$ of the respondents in Peru and majority of the respondents in Congo affirmed that antimicrobial resistance was a global problem ${ }^{4,5}$. Likewise, most of the respondents $(96.7 \%)$ knew that ineffective treatment could occur due to indiscriminate and injudicious antimicrobial use. This high level of knowledge on the role of injudicious antimicrobial use on the effectiveness of treatment agrees with findings from other studies ${ }^{10,11}$. A greater proportion $(60.9 \%)$ were aware that diseases like influenza and common cold are not 
of bacterial aetiology. However, 39\% of our respondents wrongly stated that bacteria cause common cold and flu. In contrast, only a lower proportion of $5.8 \%$ had such erroneous knowledge in a similar study among second-year medical students ${ }^{12}$. This is particularly worrisome as all our respondents had received lectures on medical microbiology which these second year students were yet to receive. Incorrect knowledge on aetiology of viral illnesses and use of antibiotics for these illnesses has also been reported from previous studies ${ }^{15}$. Such wrong knowledge may lead to inappropriate high rate of antibiotics consumption which can result in a corresponding increase in bacterial resistance to the used antibiotics ${ }^{16}$. Majority of the respondents (88\%) also admitted that they needed more education on antibiotic use and resistance. This desire for more knowledge of antimicrobial use and resistance has been reported from other studies ${ }^{17}$. Improved knowledge on antibiotic use will boost their confidence in antibiotics prescription and use. The gender of the respondents was associated with knowledge of antimicrobial usage and resistance as more of the male medical students had better knowledge of AMR than the females $(\mathrm{P}=0.035)$. Other studies among medical students did not find any relationship between gender and knowledge ${ }^{18}$.

A significant proportion of the respondents (44\%) did not practice correct use of antibiotics. About 20\% kept leftover pills at home in case they might need it later. This is in keeping with a study done amongst undergraduate students in Nigeria where 20\% reported that they kept leftover antibiotic medications for future use ${ }^{15}$. Having leftover antibiotics may imply that either the quantity purchased or the doses prescribed were more than the required dose. It could also be that the regimen was stopped without completing the prescribed doses. The act of keeping remaining antibiotics for future use is not safe and hence, should be discouraged. This is because the availability of the leftover antibiotics will encourage the use of leftover antibiotics without consulting a doctor as has been seen in other studies ${ }^{11}$. Sharing of antibiotics with others who have similar symptoms of illhealth may also arise thus further promoting self-medication. A similar study done in Pakistan reported that about $88 \%$ of respondents kept leftover pills for future use ${ }^{19}$. High rates of having leftover antibiotics at home have also been reported from other studies among medical students ${ }^{11,20}$. There is, therefore, need for pharmacists to dispense the exact quantity of drugs in a single course of antibiotics treatment rather than the whole drug pack. They should also counsel patients on the risks associated with an incomplete course of antibiotic therapy. In this study, only about $20 \%$, of our respondents consulted a doctor before starting antibiotics with most of them self-medicating and this practice could lead to antibiotic resistance. Self-medication with antibiotics is defined as the acquisition and self-administration of antibiotics with the aim of treating a perceived infection ${ }^{21}$. This practice could lead to antibiotic resistance ${ }^{3}$. Our finding is contrary to that from other studies among medical students that showed that $93 \%$ of the respondents consulted a doctor before starting an antibiotic ${ }^{10,12}$. The practice of consulting a doctor before antibiotic use in these studies could have been because these students had not been taught pharmacology and microbiology in the medical school and thus may have less knowledge and confidence in antibiotic usage. Though all the respondents in this study had been taught on the pharmacology of antibiotics, self-medication practice was still high. Studies have found a proportional relationship between self-medication and students' class level in the university ${ }^{22}$. We also found that about $22 \%$ of our respondents stopped the course of antibiotics when they felt better. Similarly, another study carried out in India reported that $13 \%$ of the respondents stopped their course of antibiotics when symptoms abated ${ }^{12}$. In contrast, higher proportions of non-completion of antibiotic course have been documented among university students in other studies. These students stopped their antibiotics medication as soon as their symptoms disappeared ${ }^{19,23}$. Thus, non-completion of prescribed antibiotic regimen is a growing problem globally and should be discouraged to reduce or delay the emergence and spread of antibiotic resistance. Only twenty-seven percent of our respondents had good practice of discarding their left-over antibiotic medications after finishing the prescribed course. This is similar to findings from another study where $30 \%$ of the medical students discarded the remaining leftover medications after completion of the antibiotic course ${ }^{10}$. Class of study in the medical school was associated with good antibiotic usage $(\mathrm{P}<0.001)$ and good antibiotics use observed to be higher among the fifth year medical students. This could be because the fifth year medical students had recently concluded teachings on medical microbiology and pharmacology in their fourth year class compared to their colleagues in the final year.

This study presents several strengths. Firstly, to the best of our knowledge, it is one of the few studies that have investigated the knowledge and practice regarding AMR and antibiotic use amongst medical school students in southeastern Nigeria. Secondly, no student refused to complete the questionnaire, resulting in a high response rate. The use of self-report could have introduced potential bias into the study; however anonymous participation was ensured to minimize socially desirable answers. This study was conducted in just one Nigerian medical school and thus its findings may not be generalizable to other medical schools.

\section{Conclusion}

This study has demonstrated that medical students in Ebonyi State University have good knowledge of antibiotic use and resistance. However, despite the good knowledge, high rates of incorrect antibiotic usage practices were noticed. Notwithstanding having a sufficient theoretical background, the students do not practice what they learn. Since they will be prescribing antimicrobial drugs following graduation as doctors, there is need to enrich existing courses and training about antimicrobial use with more emphasis on antimicrobial stewardship.

\section{Acknowledgements}

We acknowledge all the medical students who participated in the study.

\section{Conflict of Interest}

The authors do not have any conflict of interest to declare.

\section{Funding}

The authors did not receive any funding support for the study. 


\section{References}

1. Rice LB. Federal funding for the study of antimicrobial resistance in osocomial pathogens: No ESKAPE. J Infect Dis. 2008;197(8):1079108. DOI: $10.1086 / 533452$.

2. World Health Organization. Antimicrobial resistance [Internet]. Media centre. 2018. Available from: http://www.who.int/mediacentre/ factsheets/fs194/en/ [Accessd 2018 Apr 5].

3. Moongtui W, Picheansathian W, Senaratana W. Role of nurses in prevention of antimicrobial resistance. Reg Heal Forum. 2011;15(1):104-11. Available from: http://www.searo.who.int/ publications/journals/regional_health_forum/media/2011/V15n1/ rhfv15n1p104.pdf [Accessed 03/05/18]

4. García C, Llamocca LP, García K, et al. Knowledge, attitudes and practice survey about antimicrobial resistance, and prescribing among physicians in a hospital setting in Lima, Peru. BMC Clin Pharmacol. 2011;11(1):18. DOI: 10.1186/1472-6904-11-18.

5. Thriemer K, Katuala Y, Batoko B, et al. Antibiotic prescribing in DR Congo: A knowledge, attitude and practice survey among medical doctors and students. PLoS One. 2013;8(2):e55495. DOI: 10.1371/ journal.pone.0055495.

6. Ehigiator O, Azodo CC, Ehizele AO, Ezeja EB, Ehigiator L, Madukwe IU. Self-medication practices among dental, midwifery and nursing students. Eur J Gen Dent. 2013;2(1):54-7. DOI: 10.4103/22789626.106813.

7. Fadare JO, Tamuno I. Antibiotic self-medication among university medical undergraduates in Northern Nigeria. J Public Heal Epidemiol. 2011;3(5):217-20. Available at: http://www.academicjournals.org/ journal/JPHE/article-full-text-pdf/05F004B1416 [accessed 12/03/18]

8. Howard P, Nathwani D, Dyar OJ. European medical students: a first multicentre study of knowledge, attitudes, and perceptions of antibiotic prescribing and antibiotic resistance '. J Antimicrob Chemother. 2017;69:842-6. DOI: 10.1093/jac/dkt440.

9. Dyar OJ, Howard P, Nathwani D, Pulcini C. Knowledge, attitudes, and beliefs of French medical students about antibiotic prescribing and resistance. Med Mal Infect. 2013;43(10):423-30. DOI: 10.1016/j. medmal.2013.07.010.

10. Khan AK, Banu G, Reshma KK. Antibiotic Resistance and Usage-A survey on the knowledge, attitude, perceptions, and practices among the medical students of a Southern Indian teaching hospital. J Clin Diagnostic Res. 2013;7(8):1613-6. DOI: 10.7860/JCDR/2013/6290.3230.

11. Scaioli G, Gualano MR, Gili R, Masucci S, Bert F. Antibiotic use : A cross-sectional survey assessing the knowledge, attitudes, and practices amongst students of a school of medicine in Italy. PLoS One. 2015;10(4):e0122476. DOI: 10.1371/journal.pone.0122476.

12. Mahajan M, Dudhgaonkar S, Deshmukh S. A questionnaire-based survey on the knowledge, attitude and practises about antimicrobial resistance and usage among the second year MBBS students of a Teaching tertiary care Hospital in Central India. Int J Pharmacol Res. 2014;4(4):175-9. DOI: 10.7439/ijpr.

13. Spellberg B, Guidos R, Gilbert D, et al. The epidemic of antibioticrResistant infections: A call to action for the medical community from the Infectious Diseases Society of America. Clin Infect Dis. 2008;46(2):155-64. DOI: 10.1086/524891.

14. Maragakis LL, Perencevich EN, Cosgrove SE. Clinical and economic burden of antimicrobial resistance. Expert Rev Anti Infect Ther. 2008;6(5):751-63. DOI: 10.1586/14787210.6.5.751.

15. Sanya TE, Titilayo OF, Adisa R, Segun JS. Use of antibiotics among non-medical students in a Nigerian university. Afr Health Sci. 2013;13(4):1149-55. DOI: 10.4314/ahs.v13i4.41.

16. Zafar SN, Syed R, Waqar S, et al. Self-medication amongst university students of Karachi: prevalence, knowledge, and attitudes. J Pak Med Assoc. 2008;58(4):214-7. DOI: 10.12691/ajps-1-5-5

17. Minen MT, Duquaine D, Marx MA, Weiss D. A Survey of knowledge, attitudes, and beliefs of medical students concerning antimicrobial use and resistance. Microb Drug Resist. 2010;16(4). DOI: 10.1089/mdr.2010.0009.

18. Vahedian M, Faroughi F, Khakshour A, Saeidi M. Study and comparism the knowledge of medical and public health students about control and treatment of TB with (DOTS) strategy. Int J Pediatr. 2014;2(5). DOI: 10.22038/IJP.2014.2513

19. Arshad M, Resool M, Ijaz M, Hussain A. Evaluation of antibiotic use behavior in cold and flu amongst the students of Bahauddin Zakanya University Multan Pakistan. Pakistan J Pharm. 2010;20-23(1\&2):1522

20. Sawair FA, Baqain ZH, Abu Karaky A, Abu Eid R. Assessment of self-medication of antibiotics in a Jordanian population. Med Princ Pract. 2009;18(1):21-5. DOI: 10.1159/000163041.

21. Kumar N, Kanchan T, Unnikrishnan B, et al. Perceptions and practices of self-Medication among medical students in Coastal South India. PLoS One. 2013;8(8):e72247. DOI: 10.1371/journal. pone. 0072247

22. Osemene K, Lamikanra A. A study of the prevalence of selfmedication practice among university students in Southwestern Nigeria. Trop J Pharm Res. 2012;11(4):683-9. DOI: 10.4314/tjpr.v11i4.21.

23. Suaifan G, Shehadeh M, Darwish D, Al-Ijel H, Yousef A, Darwish R. A cross-sectional study on knowledge, attitude, and behaviour related to antibiotic use and resistance among medical and non-medical university students in Jordan. African J Pharm Pharmacol. 2012;6(10):763-70. DOI: $10.5897 /$ AJPP12.080 